\title{
LXIII. Extract of a memoir read in the French National Institute, on the strength of the flax of New Zealand, compared with that of the filaments of the aloe, of hemp, flax, and silk
}

\section{Labillardiere}

To cite this article: C. Labillardiere (1804) LXIII. Extract of a memoir read in the French National Institute, on the strength of the flax of New Zealand, compared with that of the filaments of the aloe, of hemp, flax, and silk , Philosophical Magazine Series 1, 17:68, 341-347, DOI: $10.1080 / 14786440408676430$

To link to this article: http://dx.doi.org/10.1080/14786440408676430

\section{Published online: 18 May 2009.}

Submit your article to this journal 5

\section{Џ Article views: 3}


liquor is reduced to and measured at that heat; and the computation from thein, though most strictly accurate in that case, will therefore be liable to some small error in the extremes of temperature; they will, however, be found to be sufficiently correct for all practical purposes. Should the legislature change the standard of prooif, they will of course become in a great measure useless as well as the instruments which are graduated from them, and new ones must therefore be calculated.

LXIII. Extract of a Memoir read in the French National Institute, on the Strength of the Flax of New Zealand, compared with that of the Filaments of the Aloe, of Hemp, Flax, and Silk. By C. Labillardiene.

I

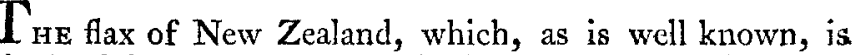
obtained from a plant of the family of the asphodela, called Phormium tenax, holds the first rank among the vegetable fibres, yet known, proper for the making of ropes. 'This fact was first made known by the celebratea Captain Cook and his illustrious fellow-navigator Sir Joseph Banks. It was afterwards confirmed by Dr. Forster, who gave a good description of the plant, which he found growing in full vigour during various excursions in New Zealand, at several parts of which he touched when he accompanied Captain Cook on his second royage round the world. A good figure of the plant may be seen in the first volume of the account of that voyage, and also in Miller's Icones Plantarum. Dr. Forster has decribed all the parts of fructification, and illustrated them with figures, in his work on the new genera of plants discovered in the South Seas.

No person, however, has ever yet attempted to ascertain how far the fibres of the Phormium tenax are superior in strength to those of hemp. This is the object of the present memoir, in which I shall compare their strength with that of the filaments of the aloe, of flax, and of silk. It is of the more importance to examine the strength of the flax of $\mathrm{New}$ Zealand, as compared with that of hemp in particular, because it might be substituted for the latter with great advantage in the navy, whereas the other substances are too scarce and too dear, or much inferior in utility.

The flax of New Zealand, which I submitted to examination in order to ascertain its strength, was given to me in exchange for toys by some of the inhabitants of that extensive country, with whom we had an intercourse, towards its 
northern point, during the voyage undertaken in search of Perouse; Ventose 22d, 1st year of the republic. The plant which produces it is of great use to these savages; and when they approached us, the first articles they exhibited were large handfuls of its leaves prepared for various purposes. Even when at a considerable distance from us they waved them with a sort of enthusiasm, as if desirous to make known to us their value, and we soon found that we had properly understood this kind of language, for they set a very high price on them when they got on board our vessel.

For my experiments I preferred these filaments to those produced from the leaves of the same plant raised in greenhouses, where the fibres certainly do not acquire so much strength as in the open air; besides, the season proper for collecting leaves capable of giving the strongest fibres can be known only by experience.

The apparatus I employed for ascertaining the strength of the different fibres which I subjected to trial consisted of two pieces of wood, ten inches in height, fixed on a plank in a vertical direction, at the distance of 6 centimeters, or 2.598 inches from each other; they were slightly rounded at the upper extremity, and on the exterior part of each was fixed a small iron cylinder, about a millimetre in diameter. To these two small cylinders I affixed the filamcnts the strength of which $I$ intended to try. They rested on each side on the rounded extremities of the pieces of wood already mentioned. I took the precaution to employ fibres of the same diameter, that is $\frac{1}{10}$ of a millimetre or 0.0443 of a line, which I verified by means of a microscope and a good micrometer, taking care to twist equally the part of the filament which I examined, having chosen it as far as possible of the same dimensions throughout its whole length. I tried the strength of it from every 8 centimetres to 8 centimetres, or every 2 inches 1):464 lines, which was the distance between the pieces of wood, and $I$ suspended from about the middle of it, by means of a wire hook well covered with hemp, a weight which I increased until the filament was broken.

I tools care that it should not be twisted, in order that I might ascertain its whole strength, for without this precaution it would have broken, as is well known, much sooner. Besides, for many reasons which it would be superfluous to mention here, I should have obtaincd results much less certain; and it is necdless to oluscrye that, in such cases, a pigorous detemination cannot be obtained, but merely an approximation. 
After having tried the strength of twelve lengths of hemp, as above described, and having divided the sum by that number, to ascertain the mean strength of cach, I found that it was equal to $16 \frac{1}{3}$, while that of the fibres of the Phormizm tenax, tried in the same state, was $23 \frac{5}{11}$. The filaments of the aloe gave only 7 , flax 113 , and silk $34 ;$ or, in other words, the fibres of hemp broke only with a weight of 400.5917 grammes, that of the flax of New Zealand by 590.5034 grammes, flax by 295.8228 grammes, and silk by $855 \cdot 9978$ grammes.

The hemp and flax which I employed for these experiments were the first fibres of the best kind produced in the department of L'Orne. I extracted, by maceration and slight friction to detach the parenchyme, the fibres of the aloe from a leaf of the Agave foetida, Lins. or the Furcrea gigantea, VENT. which was given to me by my colleague $\mathrm{C}$. Thouin.

I must here observe, that at first I took the flaments of a diameter much smaller, $\frac{1}{20}$ th of a millimetre, or 0.0221 of a line, and even less; but $I$ soon observed that it was difficult to obtain them of that tenuity without a great many inequalities and other defects, which prevented the exactness of the results ; besides, the more delicate they were, the more difficult it was to ascertain their diameter. I paid attention, therefore, to those only the diameter of which was $\frac{1}{10}$ of a millimetre.

It may, therefore, be readily conceived what advantage it would be to the navy to have ropes, the strength of which, were it confined merely to this proportion, would be almost one-half greater than that of hemp ropes. But I have no hesitation to assert that it will far exceed it ; for the fibres of the flax of New Zealand, according to a series of comparative experiments which I made on purpose to determine the tension of which they are susceptible before they break, are more tensible by one-half than those of hemp; and the principal cause of the diminution of the strength of a rope, in proportion to its being more twisted, arises in particular from the fibres of which it is composed experiencing different degrees of tension, the strength and incquality of which are increased by torsion. But it is evident that the more the fibres which enter into a rope are susccptible of tension, the less is the difference in the distribution of their strength, whence it results that the most tensible fibres, cateris parilus, will always make the best ropes.

It has been observed that certain kinds of hemp, with Y 4 stifi, 
stiff, but very strong fibres, are often capable of less resistance, when employed to make ropes, than other kinds, the fibres of which are weaker, but softer and more flexible. It is besides known, that stiff fibres break by a weak degree of torsion, which is resisted by those that have more flexibility.

To ascertain the tensibility of the fibres of the flax of New Zealand, I took six of $\frac{1}{1-}$ millimetre, or 0.0443 line in diameter, and suspended to lengths of 14 centimetres, or 5 inches 2.062 lines, a weight which I gradually increased, examining by what quantity they were extended before they broke. The sum of these quantities, divided by the number of the filaments subjected to trial, gave for quotient the mean term of the tensibility of. each. Having subjected to the same trial the filaments of the aloe, of hemp, of flax, and of silk, the results which I obtained were: for the fax 1.1279 millimetres; for the hemp 2.2558; for the flax of New Zealand 3.3837 ; for the aloe 5.6395 ; and for the silk 11.2790: so that the tensibility of flax being equal to half that of hemp will be expressed by 1 ; that of the Phormium tenax by $1 \frac{1}{2}$; that of the filaments of the aloe by $2 \frac{1}{z}$; and that of silk by 5 . It is thence seen what prodigions power of resistance is exhibited by a few threads of silk, carefully spun, as their very great tcusibility causes them all to make an effort nearly equal before they yield to the effort made to break them.

It may not be improper here to remark, that the Chinese, who make great use of silk strings for their musical instruments, have no doubt found that twisting them for that purpose hurts their strength, and also the justness of the sound, for they are manufactured without twisting; the threads of which they are composed being merely united by means of an elastic resin : on this account they are, on the first view, taken for catgut. I have no doubt that if our artists would attempt this new manufacture, their labours would be attended with success, especially as they employ with great dexterity various kinds of elastic resin ; but that extracted from the Valle of Madagascar (Vahea elastica), would be preferable to caoutchouc, which comes from Guyan, becanse the latter has a very dark tint, while the other inclines very much to a white colour. It rcadily dissolves, as is well known, in ether. Besides gum clastic extracted from several other regetables might also be employed for the same purpose.

The Phormium tenar is tar from being the only plant of the division of the monocotyledons, capable of furnishing filaments 
flaments proper for the uses of rope-making; for besides some gramineous plants, most of the palms, and all the species of the Agave, \&c. there are many others of this great division which have not yet been employed, and which might be turned to advantage, particularly several kinds of iris, the leaves of which possess very great strength.

I must here observe, that in most plants of the division of the monocotyledons, the leaves produce the filaments proper for the purposes of rope-making; and the disposition of their fibres, which is nearly parallel throughout the whole length of the leaves, will call to the remembrance of botanists the excellent memoir of our colleague Desfontaines, on the organization of the monocotyledon plants. On the other hand, in the division of the dicotyledons, the filaments employed for ropes is obtained from the bark; and it is well known, that among the great number of seetions which these vegetables contain, they are found chiefly in those of the Thymeli, Urtice, Malvacece, Tilice, and the Amentacece. The bark of a shrub of the first section (of a new kind of Pimelea) produces filaments which I have seen the inhabitants of Cape Van Diemen employ for the purpose of making ropes. These savages have so little industry, that they use them without the least preparation. They even take no advantage of a very excellent kind of flax which grows spontaneously on their coasts. The erude bark of the Pimelea abovementioned formed the handles of some baskets made of reeds, which the women at the hours of repast filled with shell-fish, diving in the sea to considerable depths, at the risk of being devoured by sharks, of of being detaincd at the bottom of the water by marine plants, some of which, and particularly the Fious pyriferus, are several hundreds of feet in length.

They employed this bark also for fastening round their bodies the skin of the kangaroo, the only clothing worn by the best dressed of these savages ; for several of them were entirely naked, though exposed to severe cold in the latis tude of $44^{\circ}$ South, and by a very strange kind of whim this vestment served only to cover the shoulders.

The Phormium tenax will succed perfectly in France, for it is found in New Zealand from lat. $34^{\circ}$ to lat. $47^{\circ}$ South, and is exposed there to very severe. frosts in the most southern part of that very large country. Moist places are better suited to it than dry, and the same may be said of most of the other Lilacei. It would thrive well in many of the maraly districts, which at present are considered as use- 
less; besides, it is a lively plant, and will require very little care. It may readily be conceived what advantages must result from the culture of this valuable plant, and particularly to the navy, as it will lighten in a very considerable degree the lading of our vessels, for the weight of the rigging in a 74-gun ship is estimated at 1714.005 myriagrammes, or 68000 pounds. The use of the flax of New Holland would lessen this weight more than one-half; and also that of the other ropes, which are above the line of flotation; and therefore the vessel would be capable of taking in a much greater quantity of provisions. Besides, it is well known that the less the diameter of the ropes above the line of flotation, the less will be the lee-way; and, therefore, these new ropes will contribute to accelerate the progress of ships of war, which will still be increased by the lightening they will experience when loaded with a less weight than usual. These ropes being smaller and lighter than those made with hemp, fewer hands will be required to manage them ; so that, if introduced, ships will need fewer men than those rigged with hemp.

It is evident also that fibres so strong and so pliable will be proper for the fabrication of different kinds of cloth, and may be substituted with advantage in our manufactories for hemp and even flax. They will no doubt retain in the loom that superiority which they have in strength over hemp. Their whiteness and silky appearance give reason to hope that cloth made of them will exceed in beauty that manufactured from flax.

All the dresses which we purchased from the savages of New Zealand were made from the fibres of their flax. To cords of the same substance they had attached different ornaments, among which were pieces of human bones, and which were suspended on their breast as a kind of trophy. They seemed to attach great value to them, and were very unwilling to part with them.

Their fishing-lines were formed of two filaments twisted together; but their nets were made from the leaves of a plant separated into filaments, without any other preparation. As their nets are of prodigious extent, for the purpose of fishing at a great distance from the coast, these savages do not make them of ropes, because this labour would require much time, and they besides find that their flax employed in this manner is sufficient.

All the piroguas which approached us had on board men armed for the most part with stones, some of them of granite, and others of serpentine, which they had attached to 
their wrists with cords of the Phormium tenax; but I must observe that these were only defensive weapons, for they did every thing in their power to engage our confidence, and soon consented to exchange these weapons for our hatchets, and for other instruments of iron, on which these warlike people set great value.

It follows from the experiments, the results of which I have here given, 1st, that the strength of the fibres of the aloe being equal to 7 ; that of flax is represented by $11 \frac{3}{4}$; that of hemp by $16 \frac{1}{3}$; that of the flax of New Zealand by $23 \frac{5}{11}$, and that of silk by 34 . But the quantity they stretch before they break is in another proportion; for that of the filaments of the aloe being equal to $2 \frac{1}{2}$; that of flax is only $\frac{1}{2}$; that of hemp 1 ; that of the flax of New Zealand $\mathbf{1} \frac{1}{2}$; and that of silk 5 . 2d, That great advantages will result from the cultivation of the New Zealand flax in France, where it will thrive exccedingly well,

IXIV. Sketch of a Geological Delineation of South America. By F. A. Von Humbold *.

$S_{\text {INCE I sent to Madrid the two first sketches of a geolo- }}$ gical delineation of South America, from the Caraccas and Nueva Valencia, I have travelled 1200 miles, and described a square between Caribe, Portocabello, Pimichin, and Esmeralda, a space comprehending above 59000 square miles, for I am not acquainted with the land between the mountain Parea and Portocabello, and between the northern coast and the valley of the Black river. In consequence of the great circumference of this district, I must content myself with delineating it in a general manner, and to avoid details, with describing the construction of the earth, the declivity of the land, the direction and inclination of the mountains, their relative ages, their similarity with the formation of those in Europe. These are the circumstances most necessary to be known in this science. We must proceed in mineralogy as in geography; we are acquainted with stones, but not with mountains; we know the materials, but we are ignorant of the whole of which they form component parts. I wish I may be able, amidst the variety

* This sketch is an extract from a paper transmitted by M. Von Humboldt from South America, together with a geological collection, to the directors of the cálinet of natural history at Madrid. It was sent also by M. Von Humboldt to Delametherie, and inserted by him in the yournal de Fbysique, vil. 53. p. 30 。 